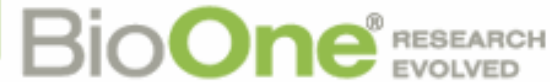

\section{Can Cage-Trap Performance in Capturing Red Foxes Be Improved by Using Different Baits and Scent Attractants?}

Author(s): Francisco Díaz-Ruiz, Miguel Delibes-Mateos \& Pablo Ferreras

Source: Annales Zoologici Fennici, 53(1-2):91-102.

Published By: Finnish Zoological and Botanical Publishing Board

DOI: http://dx.doi.org/10.5735/086.053.0208

URL: http://www.bioone.org/doi/full/10.5735/086.053.0208

BioOne (www.bioone.org) is a nonprofit, online aggregation of core research in the biological, ecological, and environmental sciences. BioOne provides a sustainable online platform for over 170 journals and books published by nonprofit societies, associations, museums, institutions, and presses.

Your use of this PDF, the BioOne Web site, and all posted and associated content indicates your acceptance of BioOne's Terms of Use, available at www.bioone.org/page/ terms of use.

Usage of BioOne content is strictly limited to personal, educational, and non-commercial use. Commercial inquiries or rights and permissions requests should be directed to the individual publisher as copyright holder. 


\title{
Can cage-trap performance in capturing red foxes be improved by using different baits and scent attractants?
}

\author{
Francisco Díaz-Ruiz ${ }^{1,2, *}$, Miguel Delibes-Mateos ${ }^{1,2,3}$ \& Pablo Ferreras ${ }^{1}$ \\ 1) Instituto de Investigación en Recursos Cinegéticos (IREC;CSIC-UCLM-JCCM), Ronda de \\ Toledo, $n^{\circ}$ 12, ES-13071 Ciudad Real, Spain ('corresponding author's e-mail: pacodi1480@ \\ hotmail.com) \\ 2) CIBIO/InBIO, Universidade do Porto, Campus de Vairão, PT-4485-661 Vairão, Portugal \\ 3) Instituto de Estudios Sociales Avanzados (IESA-CSIC), Campo Santo de los Mártires 7, \\ ES-14004 Córdoba, Spain
}

Received 20 July 2015, final version received 17 Dec. 2015, accepted 29 Dec. 2015

Díaz-Ruiz, F., Delibes-Mateos, M. \& Ferreras, P. 2016: Can cage-trap performance in capturing red foxes be improved by using different baits and scent attractants? - Ann. Zool. Fennici 53: 91-102.

Cage-trapping is one of the control methods frequently used by hunters to remove red foxes (Vulpes vulpes) in Spain, although its low efficiency and selectivity have been frequently reported. We tested the effect of the combinations of two bait types (live/ dead) and two scent attractants (fox urine/valerian extract) in order to improve the efficiency and selectivity of cage traps in central Spain. The combination of live bait and fox urine increased the efficiency of cage traps to capture red foxes in comparison with live bait alone. None of the experimental treatments led to a significant reduction in the capture rate of non-target species, selectivity levels were always low (0\%-21\%) and non-target species were captured. In view of that, the burden of releasing captured non-target animals depends ultimately on the trapper. For this reason, the use of cage traps is still questionable for managing foxes in Spain.

\section{Introduction}

The lethal control of predators is relatively widespread all over the world (Treves \& Karanth 2003, Woodroffe et al. 2005) because humans usually see these species as competitors for shared, limited resources, such as game species (e.g. Valkama et al. 2005) or livestock (e.g. Treves et al. 2004, Sangay \& Vernes 2008). In Europe, intensive predator removal has resulted in local extinctions of several species of conservation concern, and massive contractions of the geographic ranges of many others (e.g. Whitfield et al. 2003). Species of conservation concern are often removed by predator control activities because either some legal methods are not selective (e.g. Duarte \& Vargas 2001, Way et al. 2002) or some managers employ illegal, unselective methods, such as poisoning (e.g. Whitfield et al. 2003, Márquez et al. 2013).

Generally the removal of predators causes intensive social conflicts that involve conservationists, scientists and other stakeholders (Woodroffe \& Redpath 2015). In the management of such conflicts, success occurs when the outcome is acceptable to all sides and when neither party is asserting its interests to the detriment of others (Redpath et al. 2013). In view of 
that, a total ban of predator control would not be the best way to minimise conflicts between, for example, hunters and conservationists over predator management. In this regard, finding efficient and selective methods to legally reduce the numbers of some generalist/opportunistic predators could help to reduce these tensions between hunters and conservationists.

In Spain, hunting is a valuable socioeconomic activity, and one of the most widespread rural leisure activities; nearly $80 \%$ of the territory is covered by hunting estates (Arroyo et al. 2012). Spanish hunters and game managers employ several management tools to boost the numbers of small game species like European rabbits (Oryctolagus cuniculus) or red-legged partridges (Alectoris rufa) (Arroyo et al. 2012). The use of predator control is widespread in some Spanish regions (Delibes-Mateos et al. 2013, Díaz-Ruiz \& Ferreras 2013). Red foxes (Vulpes vulpes), feral cats (Felis catus), dogs (Canis lupus familiaris), and magpies (Pica pica) are the main predators legally controlled in Spain (Díaz-Ruiz \& Ferreras 2013). Nevertheless, the illegal removal of some predators of conservation concern, including raptors and carnivores, has frequently been reported (e.g. Villafuerte et al. 1998, Márquez et al. 2013).

Spanish hunters often demand more effective methods to cull predators, especially red foxes, based on their belief that current legal methods of predator control are inefficient. For example, the efficiency of cage-traps, which are one of the most frequently employed methods to legally control foxes, is usually questioned (DelibesMateos et al. 2013). In fact, scientific studies have shown that it is extremely low; capture rate ranges between 1.2 and 5 foxes per 1000 trapnights (Herranz 2000, Duarte \&Vargas 2001, Muñoz-Igualada et al. 2008). In addition, these studies have also revealed that the low selectivity of this method is far from the standards acceptable by conservationists. If cage trapping is to be used for fox control, it requires finding ways to improve both its efficiency and selectivity, given that these are not currently acceptable either for hunters or for conservationists.

In Spain, cage traps aimed at removing red foxes are usually baited with live animals (e.g. game birds), and are used without scent attractant (Duarte \& Vargas 2001, Muñoz-Igualada et al. 2008). In this context, exploring the combination of different bait types and scent attractants may help to increase the efficiency and/or selectivity of the traps. This expectation is based on two facts: (1) not all Iberian carnivores respond equally to different scent attractants (Monterroso et al. 2011), and (2) some Iberian carnivores feed exclusively on live prey (e.g. the European wildcat (Felis silvestris); Lozano et al. 2006), while others can also frequently scavenge (e.g. red fox; Díaz-Ruiz et al. 2013).

In this paper, our goal was to assess for the first time whether the combined use of different baits and scent attractants increase the selectivity and efficiency of different cage-trap types to capture red foxes in comparison with the traditional fox control method (i.e. live-bait only).

\section{Material and methods}

\section{Study areas}

Fieldwork was performed at three sites in central Spain (Ciudad Real province; one private and two public estates) during 2003, 2006 and 2007 (Table 1). The climate at the locations is typically Mediterranean, characterised by wet, mild winters and warm, dry summers with a marked drought period (source: http://www.globalbioclimatics.org/form/maps.htm). The landscape at the study sites is Mediterranean scrubland (mainly Cistus spp. in combination with holm oak, Quercus ilex, forests), mixed with cereal croplands, riparian habitats, 'dehesas' (pastureland with a savannah-like open tree layer, mainly dominated by Mediterranean evergreen oaks), and pine, Pinus spp., plantations (Table 1).

The study site selection was based on two criteria: (1) high habitat heterogeneity that favoured wildlife diversity, including both carnivore and avian predators and their prey, which allowed us to assess trap selectivity, and (2) medium to high red fox abundance, which allowed us to test trap efficiency for capturing foxes. The three study sites were situated within the distribution area of several Iberian terrestrial carnivores, such as European wildcat, stone marten (Martes foina), small-spotted genet (Genetta genetta), Eurasian badger (Meles meles) and Egyptian mongoose 
(Herpestes ichneumon) (Palomo et al. 2007). Our study sites could potentially be occupied also by raptors, such as common buzzard (Buteo buteo), goshawk and sparrowhawk (Accipiter sp.), Bonelli's eagle (Aquila fasciata), Spanish imperial eagle (Aquila adalberti), golden eagle (Aquila chrysaetos) or eagle owl (Bubo bubo) (Martí \& Del Moral 2003). No direct measure of the abundance of species that potentially could be captured in cage traps was initially available. Therefore, nocturnal spotlight-counts were performed chiefly to estimate the fox relative abundance (kilometric abundance index, KAI) at the beginning of the study and during the trapping season (Ruette et al. 2003).

\section{Cage trapping and experimental design}

We tested the efficiency and selectivity of three types of cage traps typically used by hunters in Spain for capturing foxes. These types differ in design details: Type CT01 has one entrance, one capture chamber and a cable-door connexion system that is triggered when an animal pulls the bait fixed to the end of the steel cable (Model A; see Appendix 1); this trap type was used exclusively with dead bait. Type CT02 has two entrances, one capture chamber and a lateral bait chamber. Type CT03 has two entrances, two independent capture chambers and a central bait chamber. Model B of CT01, CT02 and CT03 cage trap types have a guillotine-type door and treadle trigger mechanism. Commercially available traps of the same type may slightly differ in e.g., dimensions and mesh size (see Appendix 1).

We tested several dead and live baits. Dead baits included chicken carcasses and lamb meat, and live baits included common quails (Coturnix coturnix), red legged partridges, and helmeted guinea fowls (Numida meleagris). Dead baits were placed inside the traps and secured with wire; they were replaced weekly. Live bait were placed in an independent chamber which, depending on the model, was adjacent to, or inside the trap (see above and Appendix 1). This chamber was covered with branches to protect animals used as live bait from inclement weather. Food and water was provided ad libitum to live animals used as bait. 
We also tested two types of scent attractants previously proved as efficient for red foxes (see e.g., Saunders \& Harris 2000, Monterroso et al. 2011): red fox urine (hereafter FU; obtained from captive red foxes held at the Castilla La-Mancha University facilities) and valerian-extract solution (hereafter VAL), which contains valeric acid found in urine and anal-sac secretions of foxes (Albone \& Fox 1971, Jorgenson et al. 1978). A piece of chalk was soaked in scent attractants (ca. 1-5 $\mathrm{cm}^{3}$ ), tied to an iron stick with elastic bands, and driven into the ground inside the cage trap. Scent attractants were replenished every 3-4 days.

At each study site, we followed a randomized-block experimental design (Zar 1999), with the treatment (i.e. the combination of bait and scent attractant) randomly assigned to each trap within a block, regardless of trap type. Treatments were randomly alternated between traps, meaning that each trap received several different treatments. The average effort per treatments was 301 trap-days (range: 72-654). The minimum distance between neighbouring traps was $100 \mathrm{~m}$. Traps were placed near shrubs or other features that may increase the probability of animal presence (e.g. ponds, watercourses, edges of dense vegetation, etc.). Traps were checked each morning, starting at dawn, to avoid keeping captured animals inside the traps for more than 24 hours. Whenever possible, we checked the traps from a distance not to affect probability of capture; we only approached them to add food and water for live bait and to replace attractants.

\section{Animal handling}

Both foxes and non-target animals captured were handled by qualified researchers, supervised by wildlife veterinarians. Animals were immobilized with a combination of ketamine hydrochloride and xylazine hydrochloride following doses recommended by Seal and Kreeger (1987). Non-target animals were released at the capture site when they fully recovered from anesthesia and the veterinarian confirmed lack of serious injuries which could have compromised their survival. Red foxes were kept in captivity for subsequent behavioural experiments. All procedures were approved by the competent authority (Castilla-La Mancha Regional Government; code numbers 02-227/RN-52 and PREG-05-23).

\section{Statistical analyses}

The effects of baits and attractants on trap performance were assessed considering the parameters defined by the International Organization for Standardization (1999) for testing restraining traps for mammals. The number of foxes captured per 1000 trap-nights was used to assess trapping system efficiency (Muñoz-Igualada et al. 2008). We used two parameters related to cage-trap selectivity: (1) direct selectivity, or the percentage of foxes captured related to the total number of animals captured (including red foxes), and (2) non-target capture rate, or the number of non-target captures per 1000 trapnights (inversely related to selectivity) (MuñozIgualada et al. 2008).

Generalized Linear Mixed Models (GLMMs) with a Gaussian distribution of errors and identity link function were used to analyse the effect of different combinations of baits and scent attractants on the efficiency and selectivity of the cagetrap types. The trap with a treatment (i.e. combination of bait and scent) was considered the sample unit. Due to violations of normality and variance homogeneity of standardized residuals, dependent variables (i.e. efficiency and non-target capture rate) were square-root- $(x+1)$-transformed (Zuur et al. 2007). Fixed factors included as explanatory variables were: cage-trap type (CT01, CT02 and CT03), treatment (i.e. combination of bait and scent: live-bait only, live bait + FU, live bait + VAL, dead-bait only, dead bait + FU and dead bait + VAL) and study site. The latter was included as a fixed factor because the low number of levels (3) prevented its consideration as a random variable (Zuur et al. 2007). Since a given trap received several different treatments, trap location (a categorical variable identifying each trap position in the field, i.e. trap id) was included as a random variable in the models. The 'live-bait only' was used in our models as baseline (i.e. control), since this is the bait combination that hunters traditionally use in cage-traps in Spain. 
All statistical analyses were performed using the lme 4 package of the $\mathrm{R}$ statistical software (http://lme4.r-forge.r-project.org/). The models were obtained with the function dredge of MuMIn package (https://cran.r-project.org/web/packages/ MuMIn/index.html) and compared using the AICc criterion (Burnham \& Anderson 2002). If no single model accounted for $90 \%$ of the total model weights, we calculated the coefficients of predictor variables through model averaging (Burnham \& Anderson 2002, Arnold 2010).

\section{Results}

Red fox presence was confirmed at the three study sites although relative abundances differed among them. KAI was higher at site 2 ( 0.26 foxes $\mathrm{km}^{-1}, 42.4 \mathrm{~km}$ surveyed) than at sites 1 ( 0.016 foxes $\mathrm{km}^{-1}, 60 \mathrm{~km}$ surveyed) and 3 (0.02 foxes $\mathrm{km}^{-1}, 66.4 \mathrm{~km}$ surveyed). The European wildcat was observed only at site 1, $\left(0.016\right.$ indiv. $\left.\mathrm{km}^{-1}\right)$, and feral cats only at site 3 $\left(0.03 \mathrm{~km}^{-1}\right)$.

A total effort of 1807 trap-nights resulted in the capture of 6 red foxes and 38 non-target animals of 13 species, including carnivores, raptors, corvids, and other groups. Overall efficiency was 3.3 foxes per 1000 trap-nights, the non-target capture rate was 21 captures per 1000 trap-nights, and selectivity was $13.6 \%$ (Table 2).

The capture rate of foxes was the highest when live bait + FU were used (Fig. 1a). Four models with a total cumulative weight of $93 \%$ were included in the model averaging for capture efficiency (Table 3). According to model averaging results, only the combination live bait $+\mathrm{FU}$ significantly increased the efficiency of cage traps to capture red foxes as compared with live bait without scent attractant (Table 4). The capture rate of red foxes was higher at site 2 than at the two other sites (Table 4).

Live bait without scent attractant resulted in the highest capture rate of non-target species (Fig. 1b). The traps with dead bait + VAL did not capture non-target species (Fig. 1b). The number of captured non-target wild predators doubled when live bait instead of dead bait was used (13.61 captures per 1000 trap-nights vs. 6.48 captures per 1000 trap-nights, respec-

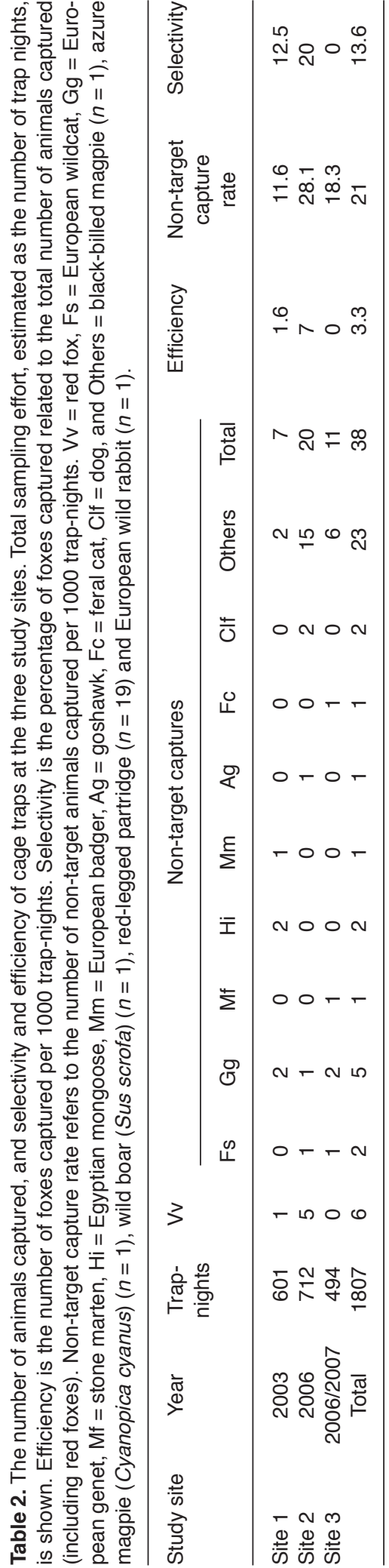



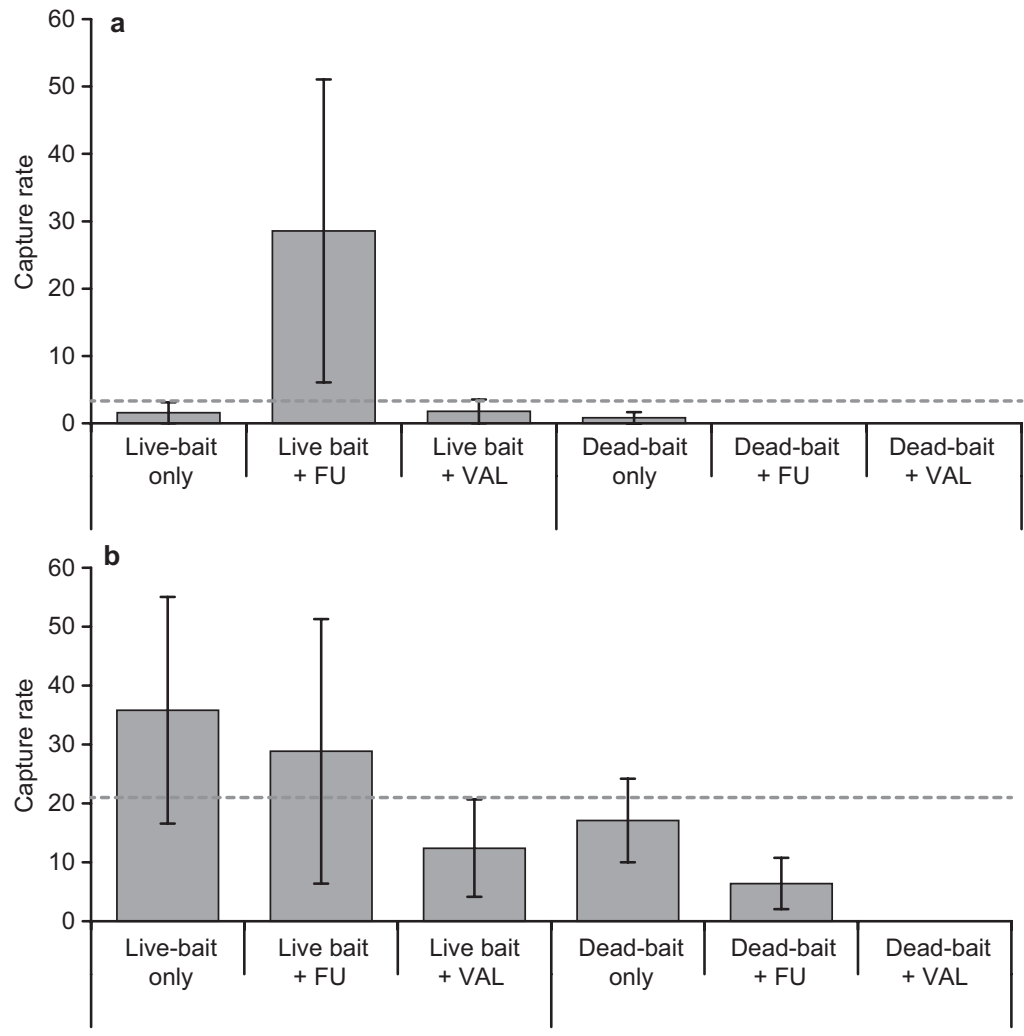

Fig. 1. Average capture rates $( \pm \mathrm{SE})$ (indv. per 1000 trap-nights) for (a) red foxes, and (b) nontarget species captured with cage traps using different combinations of bait (live and dead) and scent attractants (FU: fox urine and VAL: valerian extract) or without them. The live-bait only is traditionally used by hunters in Spain, and was used as a baseline (control) in our models. Mean capture rates for the red fox and non-target species are shown with dashed lines. tively). Four models accounting for $100 \%$ cumulative weight were included in the model averaging for capture efficiency of non-target species (Table 3). According to model averaging results, dead bait + VAL resulted in a slight decrease in the capture rate of non-target species as compared with live-bait only (Table 4). In addition, in comparison with type CT03 type, trap types
CT01 and CT02 reduced the non-target capture rates (Table 4).

\section{Discussion}

Our findings confirm the low selectivity and efficiency of cage traps used by hunters to capture

Table 3. Models explaining cage-trap efficiency for capturing foxes, and for capturing non-target animals using different treatments. Site $=$ study site and Treat $=$ combination of bait type and scent attractant. AIC values of the set of GLMMs included a total cumulative weight of at least 0.90 .

\begin{tabular}{llrcccc}
\hline & Model & df & Log-likelihood & AlCc & AAICc & Weight \\
\hline Foxes & Site $\times$ Treat & 10 & -160.558 & 344.1 & 0 & 0.57 \\
& Site & 5 & -167.725 & 346.2 & 2.12 & 0.20 \\
& Site $\times$ Treat $\times$ Trap type & 12 & -159.698 & 347.7 & 3.64 & 0.09 \\
Non-target animals & Treat & 8 & -165.216 & 348.3 & 4.24 & 0.07 \\
& Treat $\times$ Trap type & 10 & -199.816 & 422.6 & 0 & 0.49 \\
& Site $\times$ Treat $\times$ Trap type & 12 & -198.04 & 424.4 & 1.81 & 0.20 \\
& Trap type & 5 & -206.897 & 424.6 & 1.95 & 0.19 \\
& Site $\times$ Trap type & 7 & -204.982 & 425.4 & 2.81 & 0.12 \\
\hline
\end{tabular}


foxes in Spain. This is in agreement with results reported in previous studies not only for the red fox in Spain (Herranz 2000, Duarte \& Vargas 2001, Muñoz-Igualada et al. 2008), but also for other canids in North America (Way et al. 2002, Shivik et al. 2005). In particular, the capture rate of foxes obtained in our study was similar to that reported in previous studies conducted in Spain (capture rate range: $0-5.56$ foxes per 1000 trapnights; Díaz-Ruiz \& Ferreras 2013). Few studies evaluated how cage-traps performance may be improved to capture red foxes. For example, Herranz (2000) showed that live bait increase the probability of capturing foxes. This result is partially supported by our study since cage traps captured more foxes when live bait was used, but interestingly this increase was significantly higher when live bait was combined with fox urine as a scent attractant. This is not surprising as urine is used by foxes for scent marking, and plays an important role in intraspecific olfactory communication and territoriality (Macdonald 1979, Arnold et al. 2011), which may incite foxes to enter the traps. In agreement with this, traps baited with conspecific scent improved trapping efficiency of nine-banded armadillos (Dasypus novemcinctus) (Martin et al. 2014). Nevertheless, Monterroso et al. (2011) observed that captive foxes showed more interest in other attractants than in the urine of their conspecifics. This, together with the low number of foxes captured in this study suggests that additional work is needed to confirm our findings and also to test other methods to improve trap performance. The number of captured foxes could be related to their abundance, since the highest number of captures (and capture efficiency) occurred at site 2 where the highest KAI was found. Overall, the fox abundance in the study area was similar to the abundance of this species recorded in other localities within the Iberian Peninsula (KAI range: $0.001-0.47$ foxes $\mathrm{km}^{-1}$; e.g. Millán et al. 2001, Fernandez-de-Simón et al. 2015).

Although non-target species were captured using any of the bait types in combination with scent attractants (except dead bait + VAL), a substantial number of non-target predators were captured with live bait. This agrees with previous works conducted in Spain, since cage-traps baited with live animals generally captured higher numbers of non-target species, especially carnivores and raptors (Herranz 2000, Duarte \& Vargas 2001, Muñoz-Igualada et al. 2008). None of the experimental treatments achieved a significant $(p<0.05)$ reduction in the capture rate of non-target species (see Table 4). There were no captures were with dead bait + VAL. Dead bait is unattractive to a large number of predators, those which rarely scavenge (e.g. common genet, wildcat or goshawk [Accipiter gentilis]), and to nontarget species that feed on other resources (e.g. red legged partridges which were only captured in traps baited with conspecifics). In addition, valerian scent attracts a lower number of Iberian carnivores than other scent attractants (Monterroso et al. 2011).

Unlike the findings for foxes, the capture rate of non-target species differed between cagetrap types, being lower for CT01 and CT02 as compared with CT03. These results are likely more associated with the type of bait used rather than the trap type, size and design (see Appendix 1). CT01 traps were used only with dead baits, which overall resulted in fewer captures. CT02 differs from CT03 only in the position of the live-bait chamber (Appendix 1), but we do not know how this design difference could have

Table 4. Model-average coefficients and standard errors (SE) of variables included in the models explaining the efficiency of cage traps to capture red fox and non-target animals. The intercept includes Site 2 , live-bait only (which is a traditional predator control method), and CT03 cage-trap type. " $p=0.06$, "\# $p=$ $0.08{ }^{*} p<0.05,{ }^{* *} p<0.01,{ }^{* * *} p<0.001$.

\begin{tabular}{|c|c|c|c|c|}
\hline \multirow[t]{2}{*}{ Variable } & \multicolumn{2}{|c|}{ Red fox } & \multicolumn{2}{|c|}{ Non-target } \\
\hline & Parameter & SE & Parameter & SE \\
\hline Intercept & $2.16^{\star * *}$ & 0.62 & $7.68^{\star \star *}$ & 1.05 \\
\hline Site 1 & $-1.16^{\#}$ & 0.62 & -0.54 & 1.15 \\
\hline Site 3 & $-1.54^{\star *}$ & 0.51 & -0.43 & 0.86 \\
\hline \multicolumn{5}{|l|}{ Live bait } \\
\hline$+\mathrm{FU}$ & $1.93^{\star *}$ & 0.69 & -1.36 & 1.15 \\
\hline + VAL & 0.19 & 0.74 & -1.75 & 1.22 \\
\hline \multicolumn{5}{|l|}{ Dead bait } \\
\hline dead bait only & 0.00 & 0.61 & -0.58 & 1.01 \\
\hline$+\mathrm{FU}$ & 0.13 & 0.73 & -1.34 & 1.18 \\
\hline + VAL & 0.16 & 0.78 & $-2.22^{\# \#}$ & 1.26 \\
\hline СТ01 & 0.21 & 0.78 & $-4.16^{\star \star \star}$ & 1.16 \\
\hline CT02 & -0.05 & 0.53 & $-5.55^{\star \star \star}$ & 0.86 \\
\hline
\end{tabular}


affected the observed reduction in non-target species capture rate.

Recent studies have indicated that reaching acceptable outcomes to mitigate conflicts over methods for capturing animals is possible when research efforts are focused on the study of trap design or the ways they are employed. For example, Short et al. (2012) showed that a careful neck snare design improved selectivity without sacrificing efficiency to capture red foxes in the UK. In addition, modifying the cage-trap baiting strategy significantly reduced the recapture rate of an endangered non-target fox species in an island in California (USA), maintaining the capture rate of targeted feral cats (Phillips \& Winchell 2011). In our study, the combination of live bait and fox urine improved cage-trap efficiency to capture red foxes, which would likely satisfy hunters' demand. However, this baiting strategy did not reduce the capture rate of non-target species; instead, it produced the highest non-target capture rate of all. In addition, none of the other bait and scent attractant combinations significantly decreased the non-target species capture rate, and in all cases selectivity remained very low (Appendix 2), clashing with the expectations of conservationists. This, together with the small number of foxes captured in our study, suggests that further studies including trap design and baiting are required to satisfy the demands of both hunters and conservationists. Nevertheless, our results may be useful to improve the effectiveness of control strategies in other conservation contexts, where the red fox is an invasive species and the risk for native species to be caught is low. For example, poison baiting is a legal and widespread control method in Australia (Saunders et al. 2010), and the use of urine of targeted species as an attractant may contribute to increased bait uptake, therefore improving control effectiveness (see also Van Polanen Petel et al. 2001).

In conclusion, none of the bait and scent combinations tested here improved efficiency and selectivity of cage traps for catching red foxes, and in addition non-target species of conservation concern were captured. According to these results, the use of cage traps for fox management in hunting estates within central Spain is not recommended. Recently, new capture sys- tems for foxes have been developed and tested in Spain, all of which resulted in a higher efficiency than cage traps (Muñoz-Igualada et al. 2008, 2010). Among these methods, the Collarum restraining device (a propelled neck snare) was the most selective quite efficient device (MuñozIgualada et al. 2008). This system may be a good alternative to other fox control methods, such as cage traps or leg snares, (Shivik et al. 2005, Muñoz-Igualada et al. 2008, 2010). Above all, any fox management should be carried out only by trained and qualified personnel and always monitored by wildlife authorities.

\section{Acknowledgements}

This study was funded by Consejería de Medio Ambiente of Junta de Comunidades de Castilla-La Mancha. Special thanks go to landowners who facilitated access to their game estates, and to the field staff of the regional government of Castilla-La Mancha. Thanks to people who assisted us during the fieldwork, especially to S. Luna and L.E. Mínguez. We are indebted to veterinarians O. Rodríguez, M. Reglero and R. Sobrino who examined the captured animals. Two anonymous reviewers provided helpful comments on a previous version of the manuscript. B. Berzosa carefully revised the English text. F. Díaz-Ruiz received a postdoctoral contract financed by the European Social Fund (ESF) and Junta de Comunidades de Castilla-La Mancha (Operational Programme FSE 2007/2013). M. Delibes-Mateos was supported by the Talentia Postdoc Program launched by the Andalusian Knowledge Agency, and co-funded by the European Union's Seventh Framework Program, Marie Skłodowska-Curie actions (COFUND, Grant Agreement no. 267226) and the Ministry of Economy, Innovation, Science and Employment of Junta de Andalucía.

\section{Ethical standards}

This work was performed in compliance with current Spanish legislation, and follows the European Union's recommendations regarding animal welfare. All procedures were carried out with appropriate permits, provided by the concerned institutions (Castilla-La Mancha Regional Government; code numbers 02-227/RN-52 and PREG-05-23).

\section{References}

Albone, E. S. \& Fox, M. W. 1971: Anal gland secretion of the red fox. - Nature 233: 569-570.

Arnold, T. W. 2010: Uninformative parameters and model 
selection using Akaike's information criterion. - Journal of Wildlife Management 74: 1175-1178.

Arnold, J., Soulsbury, C. D. \& Harris, S. 2011: Spatial and behavioural changes by red foxes (Vulpes vulpes L., 1758 ) in response to artificial territory intrusion. Canadian Journal of Zoology 89: 808-815.

Arroyo, B., Delibes-Mateos, M., Díaz-Fernández, S. \& Viñuela, J. 2012: Hunting management in relation to profitability aims, red-legged partridge hunting in central Spain. - European Journal of Wildlife Research 58: 847-856.

Burnham, K. P. \& Anderson, D. R. 2002: Model selection and multimodel inference: a practical information-theoric aproach, 2nd ed. - Springer, New York.

Delibes-Mateos, M., Díaz-Fernández, S., Ferreras, P., Viñuela, J. \& Arroyo, B. 2013: The role of economic and social factors driving predator control in small game estates in central Spain. - Ecology and Society 18: 28.

Díaz-Ruiz, F., Delibes-Mateos, M., García-Moreno, J. L., López-Martín, J. M., Ferreira, C. \& Ferreras, P. 2013: Biogeographical patterns in the diet of an opportunistic predator, the red fox Vulpes vulpes in the Iberian Peninsula. - Mammal Review 43: 59-70.

Díaz-Ruiz, F. \& Ferreras, P. 2013: Conocimiento científico sobre la gestión de depredadores generalistas en España: el caso del zorro (Vulpes vulpes) y la urraca (Pica pica). - Ecosistemas 22: 40-47.

Duarte, J. \& Vargas, J. M. 2001: ¿Son selectivos los controles de depredadores en los cotos de caza? - Galemys 13: $1-9$.

Fernandez-de-Simon, J., Díaz-Ruiz, F., Rodriíguez-de la Cruz, M., Delibes-Mateos, M., Villafuerte, R. \& Ferreras, P. 2015: Can widespread generalist predators affect keystone prey? A case study with red foxes and European rabbits in their native range. - Population Ecology 57: 591-599.

Herranz, J. 2000: Efectos de la depredación y del control de depredadores sobre la caza menor en Castilla-La Mancha. - Ph.D. thesis, Autónoma University, Madrid.

International Organization for Standardization 1999: TC191. Animal (mammal) traps. Part 5, methods for testing restraining traps. International Standard ISO/DIS 10990-5. - International Organization for Standardization, Geneva, Switzerland.

Jorgenson, J. W., Novonty, M., Carmack, M., Copland, G. B., Wilson, S., Katona, S. \& Whitten, W. K. 1978: Chemical scent constituents in the urine of the red fox (Vulpes vulpes) during the winter season. - Science 199: 796-798.

Lozano, J., Moleón, M. \& Virgós, E. 2006: Biogeographical patterns in the diet of the wildcat, Felis sylvestris Schreber, in Eurasia, factors affecting the trophic diversity. Journal of Biogeography 33: 1076-1085.

Macdonald, D. W. 1979: Some observations and field experiments on the urine marking behaviour of the red fox, Vulpes vulpes L. - Zeitschrift fur Tierpsychologie 51: $1-22$.

Márquez, C., Vargas, J. M., Villafuerte, R. \& Fa, J. H. 2013: Risk mapping of illegal poisoning of avian and mammalian predators. - The Journal of Wildlife Management
77: 75-83.

Martí, R. \& Del Moral, J. C. 2003: Atlas de las aves reproductoras de España. - Dirección General de Conservación de la Naturaleza-Sociedad Española de Ornitología, Madrid.

Martin, J. A., Marshall, C., Belant, J. L., Cagle, S. \& West, B. C. 2014: New live-trapping method improves capture rates for nine-banded armadillos. - Wildlife Biology in Practice 10: 149-154.

Millán, J., Gortázar, C., Marco, J. \& Escudero, M. A. 2001: Carnívoros detectados mediante recorridos nocturnos en Aragón. - Galemys 13: 25-36.

Monterroso, P., Alves, P. C. \& Ferreras, P. 2011: Evaluation of attractants for non-invasive studies of Iberian carnivore communities. - Wildlife Research 38: 446-454.

Muñoz-Igualada, J., Shivik, J. A., Domínguez, F. G., Lara, J. \& González, L. M. 2008: Evaluation of cage-traps and cable restraint devices to capture red foxes in Spain. Journal of Wildlife Management 72: 830-836.

Muñoz-Igualada, J., Shivik, J. A., Domínguez, F. G., González, L. M., Moreno, A. A., Olalla, M. F. \& García, C. A. 2010: Traditional and new cable restraint systems to capture fox in central Spain. - Journal of Wildlife Management 74: 181-187.

Palomo, L. J., Gisbert, J. \& Blanco, J. C. 2007: Atlas y libro rojo de los mamíferos de España. - SECEM-SECEMU, Madrid.

Phillips, R. B. \& Winchell, C. S. 2011: Reducing nontarget recaptures of an endangered predator using conditioned aversion and reward removal. - Journal of Applied Ecology 48: 1501-1507.

Redpath, S. M., Young, J., Evely, A., Adams, W. M., Sutherland, W. J., Whitehouse, A., Amar, A., Lambert, R. A., Linnell, J. D. C., Watt, A. \& Gutiérrez, R. J. 2013: Understanding and managing conservation conflicts. Trends in Ecology and Evolution 28: 100-109.

Ruette, S., Stahl, P. \& Albaret, M. 2003: Applying distancesampling methods to spotlight counts of red foxes. Journal of Applied Ecology 40: 32-43.

Sangay, T. \& Vernes, K. 2008: Human-wildlife conflict in the Kingdom of Bhutan, patterns of livestock predation by large mammalian carnivores. - Biological Conservation 141: 1272-1282.

Saunders, G. \& Harris, S. 2000: Evaluation of attractants and bait preferences of captive red foxes (Vulpes vulpes). Wildlife Research 27: 237-243.

Saunders, G. R., Gentle, M. N. \& Dickman, C. R. 2010: The impacts and management of foxes Vulpes vulpes in Australia. - Mammal Review 40: 181-211.

Seal, U. S. \& Kreeger, T. J. 1987: Chemical immobilization of furbearers. - In: Novak, M., Baker, J. A., Obbard, M. E. \& Malloch, B. (eds.), Wild furbearer management and conservation in North America: 191-215. Ontario Trappers Association, Ontario.

Shivik, J. A., Martin, D. J., Pipas, M. J., Turnan, J. \& DeLiberto, T. J. 2005: Initial comparison, jaws, cables, and cage-traps to capture coyotes. - Wildlife Society Bulletin 33: 1375-1383.

Short, M. J, Weldon, A. W., Richardson, S. M. \& Reynolds, J. C. 2012: Selectivity and injury risk in an improved neck 
snare for live-capture of foxes. - Wildlife Society Bulletin 36: 208-219.

Treves, A. \& Karanth, K. U. 2003: Human-carnivore conflict and perspective on carnivore management worldwide. - Conservation Biology 17: 1491-1499.

Treves, A., Naughton-Treves, L., Harper, E. K., Mladenoff, D. J., Rose, R. A., Sickley, T. A. \& Wydeven, A. P. 2004: Predicting human-carnivore conflict, a spatial model derived from 25 years of data on wolf depredation on livestock. - Conservation Biology 18: 114-125.

Valkama, J., Korpimaki, E., Arroyo, B., Beja, P., Bretagnolle, V., Bro, E., Kenward, R., Mañosa, S., Redpath, S. M., Thirgood, S. J. \& Viñuela, J. 2005: Birds of prey as limiting factors of gamebird populations in Europe, a review. - Biological Reviews 80: 171-203.

Van Polanen Petel, M., Marks, C. A. \& Morgan, D. G. 2001: Bait palatability influences the caching behaviour of the red fox (Vulpes vulpes). - Wildlife Research 28: 395-401.

Villafuerte, R., Viñuela, J. \& Blanco, J. C. 1998: Extensive predator persecution caused by population crash in a game species, the case of red kites and rabbits in Spain. - Biological Conservation 84: 181-188.

Way, J. G., Ortega, I. M., Auger, P. J. \& Strauss, E. G. 2002: Box-trapping eastern coyotes in southeastern Massachusetts. - Wildlife Society Bulletin 30: 695-702.

Whitfield, D. P., McLeod, D. R. A., Watson, J., Fielding, A. H. \& Haworth, P. F. 2003: The association of grouse moor in Scotland with the illegal use of poisons to control predators. - Biological Conservation 114: $157-163$

Woodroffe, R., Thirgood, S. \& Rabinowitz, A. 2005: People and wildlife. Conflict or coexistence? - Cambridge University Press, United Kingdom.

Woodroffe, R. \& Redpath, S. M. 2015: When the hunter becomes the hunted. - Science 348: 1312-1314.

Zar, J. H. 1999: Biostatistical analysis. - Upper Saddle River, New Jersey.

Zuur, A. F., Ieno, E. N. \& Smith, G. M. 2007: Analysing ecological data. - Springer, New York. 
Appendix 1. Design and description of the cage traps used in this study. All trap models have a trigger mechanisms based on a guillotine-type door and a tread trigger system, except Model A (CT01 type) that has a cable-door connexion system that is triggered when the animal pulls the bait fixed to the end of the steel cable.
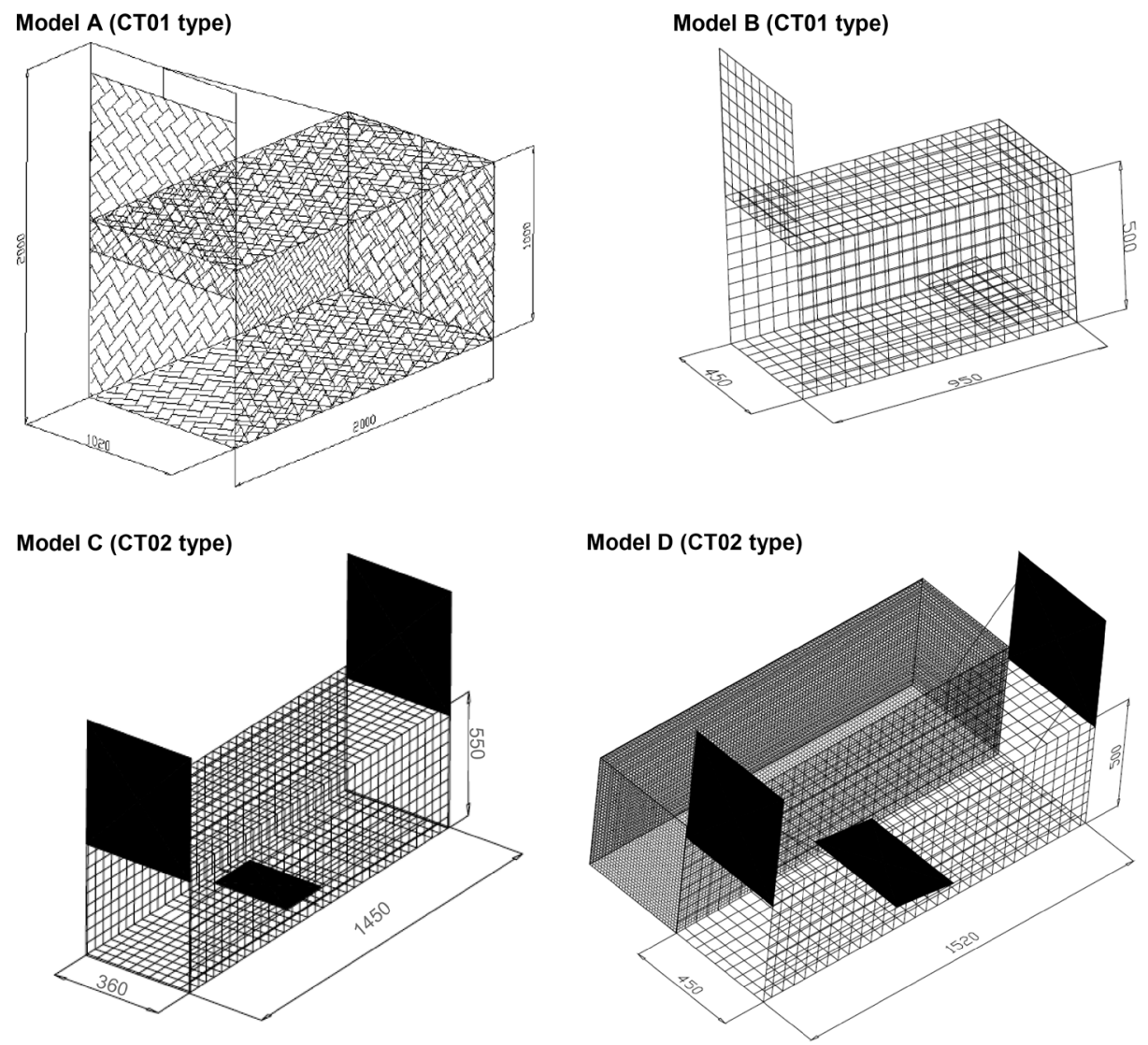

Model E (CT03 type)

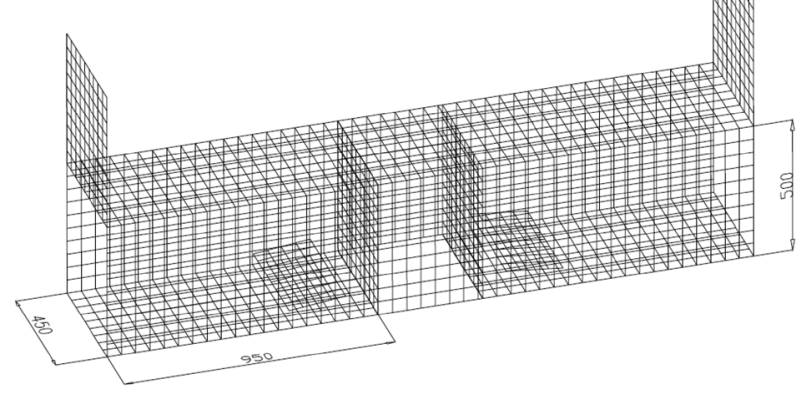

\begin{tabular}{lcccc}
\hline Model & $\begin{array}{c}\text { Size }(\mathrm{mm}) \\
(\text { width } \times \text { length } \times \text { height })\end{array}$ & $\begin{array}{c}\text { Mesh size } \\
(\mathrm{mm})\end{array}$ & Capture entrances & Live bait chamber \\
\hline A & $1020 \times 2000 \times 1000$ & $40 \times 40$ & 1 & no \\
B & $450 \times 950 \times 500$ & $50 \times 50$ & 1 & no \\
C & $360 \times 1450 \times 550$ & $46 \times 46$ & 2 & lateral \\
D & $450 \times 1520 \times 500$ & $52 \times 52$ & 2 & lateral \\
E & $450 \times 2300 \times 500$ & $50 \times 50$ & 2 & central
\end{tabular}


Appendix 2. Results obtained for each bait and attractant combination, and for each trap-type and bait + attractant combination (CT type). Effort = number of trap-nights, Efficiency = foxes per 1000 trap-nights, NTcr = non-target per 1000 trap-nights, $-=$ incalculable, $\mathrm{nt}=$ not tested.

\begin{tabular}{|c|c|c|c|c|c|c|c|c|}
\hline & \multirow[t]{2}{*}{ Bait } & \multirow[t]{2}{*}{ Attractant } & \multirow[t]{2}{*}{ Effort } & \multicolumn{2}{|c|}{ Captures } & \multirow[t]{2}{*}{ Efficiency } & \multirow[t]{2}{*}{ NTcr } & \multirow[t]{2}{*}{ Selectivity } \\
\hline & & & & Fox & Non-target & & & \\
\hline \multicolumn{9}{|l|}{ Bait } \\
\hline \multirow[t]{3}{*}{ Live } & & Live-bait only & 434 & 1 & 14 & 2.3 & 32.3 & 7 \\
\hline & & $+\mathrm{FU}$ & 205 & 3 & 11 & 14.63 & 53.66 & 21 \\
\hline & & $+\mathrm{VAL}$ & 243 & 1 & 4 & 4.11 & 16.46 & 20 \\
\hline \multirow[t]{3}{*}{ Dead } & & Dead-bait only & 654 & 1 & 7 & 1.53 & 10.7 & 13 \\
\hline & & $+\mathrm{FU}$ & 199 & 0 & 2 & 0 & 10.05 & 0 \\
\hline & & + VAL & 72 & 0 & 0 & 0 & 0 & - \\
\hline \multicolumn{9}{|l|}{ CT type } \\
\hline \multirow[t]{6}{*}{ CT01 } & Dead & Dead-bait only & 303 & 1 & 4 & 3.3 & 13.2 & 20 \\
\hline & & $+\mathrm{FU}$ & 120 & 0 & 1 & 0 & 8.33 & 0 \\
\hline & & + VAL & 16 & 0 & 0 & 0 & 0 & - \\
\hline & Live & Live-bait only & $\mathrm{nt}$ & nt & nt & nt & nt & nt \\
\hline & & $+\mathrm{FU}$ & nt & nt & nt & $\mathrm{nt}$ & nt & nt \\
\hline & & $+\mathrm{VAL}$ & nt & nt & nt & nt & nt & nt \\
\hline \multirow[t]{6}{*}{ СT02 } & Dead & Dead-bait only & 343 & 0 & 2 & 0 & 5.83 & 0 \\
\hline & & $+\mathrm{FU}$ & 56 & 0 & 0 & 0 & 0 & - \\
\hline & & + VAL & 48 & 0 & 0 & 0 & 0 & - \\
\hline & Live & Live-bait only & 297 & 0 & 2 & 0 & 6.73 & 0 \\
\hline & & $+\mathrm{FU}$ & 133 & 1 & 0 & 7.52 & 0 & 100 \\
\hline & & $+\mathrm{VAL}$ & 157 & 1 & 0 & 6.37 & 0 & 100 \\
\hline \multirow[t]{7}{*}{ СТ03 } & Dead & Dead-bait only & 8 & 0 & 1 & 0 & 125 & 0 \\
\hline & & $+\mathrm{FU}$ & 23 & 0 & 1 & 0 & 43.48 & 0 \\
\hline & & + VAL & 8 & 0 & 0 & 0 & 0 & - \\
\hline & Live & Live-bait only & 137 & 1 & 12 & 7.3 & 87.59 & 8 \\
\hline & & $+\mathrm{FU}$ & 72 & 2 & 11 & 27.78 & 152.78 & 15 \\
\hline & & $+V A L$ & 86 & 0 & 4 & 0 & 46.51 & 0 \\
\hline & Total & & 1807 & 6 & 38 & 2.9 & 21 & 13.6 \\
\hline
\end{tabular}

